\title{
Outstaffing in innovative project management: theoretical and practical aspects
}

\author{
Hanna Matukova \\ Economic Institute of Kyiv National \\ Economic University named after \\ Vadym Hetman, Ukraine \\ Kryvyi Rih, Ukrain \\ deborah88@ukr.net
}

\author{
Natalia Bahashova* \\ Economic Institute of Kyiv National \\ Economic University named after \\ Vadym Hetman, Ukraine \\ Kryvyi Rih, Ukraine \\ bahashova_nv@kneu.dp.ua
}

\author{
Liliya Korchevska \\ Kherson National Technical University \\ Kherson, Ukraine \\ https://orcid,org/0000-0002-0720-9929
}

\begin{abstract}
The article analyzes various approaches to defining an innovative project and reflects peculiarities of its management relating to its life cycle stages. Components of an innovative project are determined. Advantages of the outstaffing system and reasons for its slow development in Ukraine are under study. Outstaffing in innovative project management is under detailed consideration.
\end{abstract}

Keywords - innovative project, project management, innovative project management, outstaffing.

\section{FORMULATION OF THE PROBLEM}

Project management is one of the most complicated trends of innovative activity as there are changes in project content and operations at various project stages, that calling for its structure transformations. To make innovative project management efficient, it is necessary to determine and consider some specific features of a project life cycle. Project management incorporates methods and technologies of control over human, material and financial resources. It prioritizes one's abilities to consider and align interests of multiple participants, solve industrial problems in a new way, find efficient solutions under conditions of uncertainty and risks. Application of outstaffing methods implies recruiting some employees through outside companies that are formal employers ensuring routine staff activity, salary accounting and payment, tax transfer and law norms observation.

\section{DEGREE OF PROBLEM DEVELOPMENT}

If innovative project management is efficient enough, national managers focus on problems of distributing functions among project participants, comparing their interests, defining the degree of their satisfaction through considering peculiarities of the project life cycle. Yet, there are no scientific papers and researches reflecting interrelation of efficient project management and monitoring of its participants' interests as well as peculiarities of the project life cycle fully and systematically. Such authors as Yokhna, Tverezovska, Rach, Rossol and others studied the above mentioned aspects of the problem.

The research aims at reviewing the notion of an innovative project through considering various approaches to its definition. The paper reflects specific features of innovative project management taking account of its life cycle stages and determining its components. Advantages of the outstaffing system and reasons for its slow development in Ukraine are also under study.

\section{STATEMENT OF THE MAIN RESEARCH MATERIAL}

An innovative project is an object of innovative activity. After generalizing definitions provided by innovative management specialists, we can conclude that innovation is interpreted from two points of view - as a process of goal achieving and as a result.

The theory of project management emerged in the 1930s provoked by methods of coordinating engineering of largescale projects in the USA in the aircraft (US Air Corporation) and oil and gas (Exxon) industries. The modern concept of management was formed in the 1950s in the USA and it began developing in the 1960s, that resulting in project management being an independent professional sphere, a complex subject aimed at implementing various projects through specific methods [5].

The project management process includes the following functions are in Figure1.

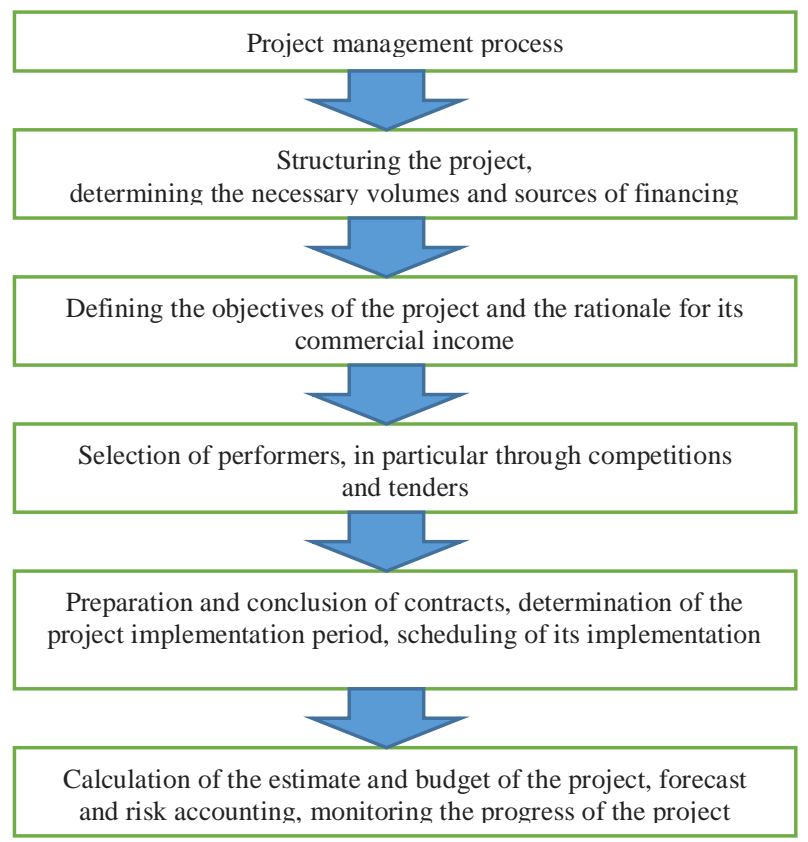

Fig. 1. Project management process functions $[\mathrm{H}$. Matukova, N. Bahashova, L. Korchevska]. 
Practices of advanced countries indicate that project management methods are the only ones efficient enough to implement innovations. Project management is a mechanism of efficient planning of investments, satisfaction of customers' expectations while providing competitive advantages, transparent management and elaborating new ideas (products, services, technologies).

Crises provoke new projects and essential changes on the market. Application of modern project management methods is the best, tried and tested way of implementing changes in a fast, transparent and efficient way [2].

The world best practices offer a set of innovative management tools for developing and implementing target programmes and projects:

- outsourcing as delegation of certain functions to another company specializing in a corresponding sphere;

- benchmarking as studying the best management practices and implementing them in one's own activity;

- reengineering as fundamental reinterpretation of one's activity and appropriate actions aimed at critical changes;

- outstaffing as reducing a company's expenditures and risks associated with its personnel in order to solve various problems of project implementation such as restriction of staff and budget resources, etc.

The outstaffing system helps enterprises to solve the following tasks: to regulate the number of employees, without going beyond the official staffing table; to provide the temporary need of the company for highly qualified specialists or for workers with a rare specialty in the implementation of short and medium-term projects for an external customer; find a replacement for the employees of the enterprise, for example, for the period of holidays or holidays; to satisfy the enterprise's need for a large number of low-skilled workers for a short time (for example, for advertising and marketing campaigns). The main goal of outstaffing services is to resolve issues related to the optimization of staffing, as well as to reduce the risks associated with solving problems related to the implementation of projects. The advantages of the outstaffing system include improving a company's economic model; managers' focusing on key areas of their activity; reducing document flows, eliminating the need to put employees officially on the staff during their probation to assess their potential without taking any responsibility, reducing loads on staff services of the enterprise or eliminating them completely; reducing loads on the accounting department of the enterprise; reducing insurance and other unforeseen risks associated with the staff; reducing the number of staffed employees, etc.

While an enterprise is evolving, its strategy may be changing, according to various scenarios of the development of the enterprise and its market success in the market. Thus, either an innovative project team or an anti-crisis team can be formed to develop an innovative project. An innovative project is a set of engineering, production, economic and managerial steps united by a single goal. It consists of several research-production stages according to available resources, terms and executors and is carried out by integrated management.

During crises, many companies use anti-crisis projects and strategies by analyzing their activity through the "client- company-competitor" principle. Short-term PR projects are advisable in the first eight working hours. The following typical steps of employees in charge are considered: creating a special anti-crisis team in the shortest time possible with the top manager as its leader taking all responsibility for crisis overcoming; fulfilling instructions of the anti-crisis team or anti-crisis departments; recruiting an outside company temporarily (outstaffing). The survival strategy during crises can be considered prevailing in the recent decade. Most scholars think that this strategy is unable to overcome crises if it is not based on the development strategy. As a rule, while solving a company's survival problem, managers apply outstaffing methods through transferring some of the company employees to a recruiter or a leasing agency. Transferred employees stay at their former working places, yet a leasing company acts as their employer in terms of payroll accounting and social guarantees. In a broad sense, outstaffing implies an agreement between a company and a recruiter that provides a customer with some employees for a determined period [3]. Recruiters consider outstaffing a universal technology applicable to solving crisis and other issues at any enterprise. Today, many companies apply outstaffing to reducing expenditures and risks associated with personnel and solving various staff and budget problems. As for outstaffing in project management, it is treated as providing a company with the staff characterized by relevant knowledge, skills and experience [6].

The following companies can serve as examples of successful outstaffing. MTC is the largest mobile operator in the Eastern and Central Europe region. All the company operators, many executors and some lower-level employees are holding lease contracts for personnel (outstaffing). Alfa Bank, the leading financing and credit company of Ukraine hires over 100 employees serving about 51 thousand customers and 2.9 million consumers. These workers are officially on the staff of VentraEmployment. RenessansKapital employs insurance agents and lower-level managers under outstaffing contracts. Phillips uses outstaffing merchandizers as well. Procter \& Gamble hires storage workers, while Kyivstar employs call-centre workers and lower-level managers in a similar way.

On the Ukrainian market, outstaffing is slow to be introduced in spite of the fact that many companies employ temporary workers as outstaffing increases efficiency of their activity. It is caused by the lack of companies providing outstaffing services and the absence of a relevant legal basis. Basic outstaffing customers are foreign companies trying to solve the problem of staff deficiency in Ukraine. They usually employ sales staff and employees at resident companies to work for their distributor or a company specially created to sell marketing cycle products. Outstaffing services are becoming more widespread at national companies in general and at project management ones in particular. Enterprises apply outstaffing services to employing shift employees and when the available staff is too large. Managers find multiple benefits from reducing salary and legal expenses and avoiding conflicts with trade unions. The main prerequisites of applying outstaffing include the need for reducing the current staff and administrative and financial loads with direct control over employees retained; a desire to avoid responsibility for 
employees and get a highly qualified negotiator in labour and tax inspectorate relations; a desire to enhance flexibility in personnel control and the amount of labour force relevant to the real work amount $[8,9]$.

Outstaffing efficiency is much dependent upon conditions and the character of an agreement between an enterprise and a recruiter. The agreement determines basic rights and duties of an executer and a customer. The executer acts as an employer for the personnel employed by the customer and is in charge for paying personal income taxes and deductions to legally established funds [6].

Advantages of the outstaffing system include improvement of a company's economic model; managers' focusing on key trends of their activity; reduced paper load; no need for off-the-books employment for trial engagement to assess one's working potential. The enterprise strategy can change in the course of its development and according to its various scenarios and market success, either an innovative project team or an anti-crisis team is formed. An innovative project is a set of technical, industrial, economic and managerial steps united to achieve a single general (main) goal. It comprises several stages of the 'research-production' process conformed to available resources, terms and executers and performed by integrated management [4].

According to some other researchers, it is a system of interrelated goals and programmes of their achievement as a set of scientific, research, design, industrial, managerial, financial, economic and other steps, which are accompanied by relevant design documentation to enhance solution of a particular scientific and research task (problem) expressed quantitatively, thus facilitating innovations [7]. Yokhna and Stadnyk consider an innovative project to be a set of interrelated steps developed to create, produce and promote new hi-tech products under established resource constraints [1].

If a project is developed by a design company, its participants include a customer (any economic entity) making a contract with a design company, designers knowing modern management methods and means, methods of research and system analysis, experience in management and communication skills to deal with professionals of various ranks and spheres. Observance of these requirements calls for the necessity to select and train researchers and analysts as their activity determines efficiency of project management.

In innovative management, project management is one of the most complicated activities as on its various development stages, goals, investments and often technologies change. If the life cycle of a company's product is stable, innovative management focuses on improving production and marketing. Under aggravated price competitiveness, managers tend to focus more on either decreasing expenses or increasing product quality, that demanding technological innovation management.

If the life cycle of a product is completed, diversification is required through relevant project management. Thus, a project life cycle is a basic element of the innovative project management concept reflecting project development and comprising multiple operations on various stages of project preparation, implementation and exploitation.
The group size in project teams, their interrelation and centralization degree depend on the project scale - the more completed innovations are, the more complicated the managerial structure is. The project contingent, their roles, functions and duties are determined by the project type, its scale and complexity as well as stages of its life cycle. Project management comprises the following functions: defining project goals; structuring a project; determining necessary funding amount and sources; selecting executers through tenders and contests; preparing and making contracts; making estimates and budgets; forecasting and considering risks; controlling observation of project terms, etc.

Basic components of an innovative project within various approaches to its definition are in Figure 2.

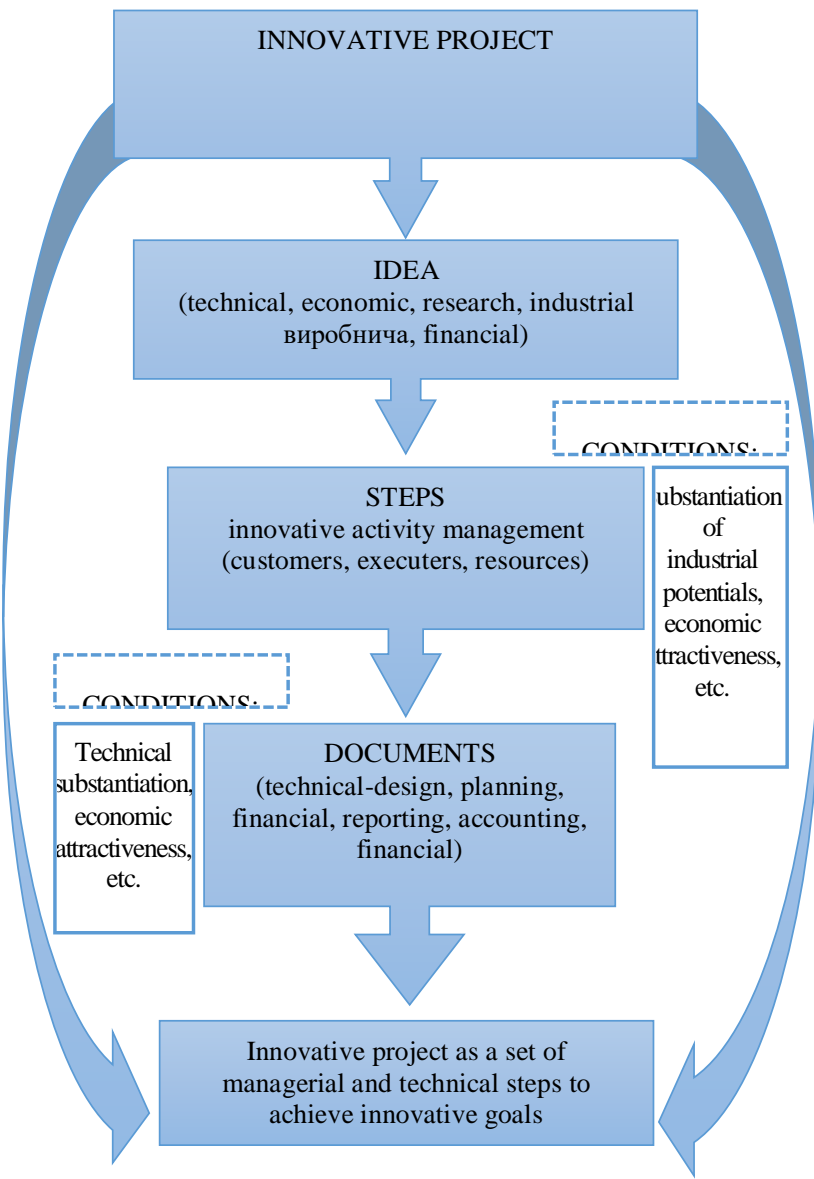

Fig. 2. Basic components of an innovative project [H. Matukova, N. Bahashova, L. Korchevska].

There is a notion of projects switching to outstaffing, which involves forming a project register; planning basic parameters of projects and controlling their costs; forming project teams and controlling project personnel; conducting tenders and selecting suppliers; external monitoring of projects, controlling changes and reporting; project management; developing and maintaining software support; juridical support; solving problems efficiently; managing risks; providing consulting and methodological support for customer's personnel; developing the corporate project management system, etc. Decisions on outstaffing of project management are made on initial stages of project 
implementation, yet sometimes it requires urgent intrusion of project managers when the project has been launched.

Outstaffing enables the following benefits for an enterprise: fulfilling functions through outstaffing professionally to avoid various mistakes and losses; providing an opportunity to modify certain project stages in case of their incorrect completion or a necessity to change something; saving financial resources to retain company's own professionals (salaries, wages, deductions, leaves of absence, sick leaves, professional certification and licensing, etc.; improved control over resources, informational support of project management, reduced implementation terms of projects and their increased efficiency [10].

Outstaffing enables the following benefits for an enterprise: fulfilling functions through outstaffing professionally to avoid various mistakes and losses; providing an opportunity to modify certain project stages in case of their incorrect completion or a necessity to change something; saving financial resources to retain company's own professionals (salaries, wages, deductions, leaves of absence, sick leaves, professional certification and licensing, etc.; improved control over resources, informational support of project management, reduced implementation terms of projects and their increased efficiency.

Ukrainian enterprises in Dnepropetrovsk region investigated into the above methods of staff restriction and concluded that Promahrehat was a regional division of PROMSTAR. Promahrehat is evolving with current operations increasing. The company staff cannot cope with increased orders, yet the corporate policy of PROMSTAR strictly limits further staff expansion.

After failures of two important orders for \$200 000 within a month, Promahrehat employed 6 workers of various levels under outstaffing conditions. Eight months later, the number of orders performed by Promahrehat increased as the company stopped losing orders due to the efficient outstaffing system, thus facilitating its own economic growth. The company spent \$ 48912 as in $S=I+T+U_{1}+U_{2}=24000+8592+3360+12960=48912 \$$ where $I=24000$ is new workers' salary, $\$ ; T=8592$ is taxes for the salary, $\$ ; U_{1}=70 * 8 * 6=3360$ is outstaffing costs, $\$ ; U_{2}=1000 * 12 * 6 * 18 \%=12960$ is costs for recruiting six employees with the $\$ 1000$ monthly salary.

With the mentioned average level of orders and extra \$ 200000 per month on the initial stage, the income deficiency could make \$ 1600000 within eight months, while total staff expenditures to obtain this income would make over $3 \%$.

Mining and concentration enterprises of Kryvyi Rih, Ukraine, were engaged into innovative and project activity for the period of 12 or 18 months. Each project required employees. The problem was that after finishing the project, most employees (up to 80\%) engaged were discharged and the company suffered from auxiliary expenditures on severance pays. The company decided to outstaff the employees engaged in two projects. There were 25 and 18 employees outstaffed for 14 and 10 months correspondingly.
After finishing the projects, the company cancelled the contract with the external provider and did not pay any severance pays.

Thus, by using outstaffing, the company reduced expenditures due to compensation payments for the finished projects. As for the two mentioned projects, the compensation payments due to staff discharge could make \$ 42000 and \$25000 accordingly. The total cost of the external provider's services made \$ 31500 and \$ 13500 accordingly totaling $\$ 45000$. The net economic savings made over $\$ 22000$ or $33 \%$.

Thus, outstaffing of project management positively affects economic indices of projects and enterprises implementing them.

\section{CONCLUSIONS AND OFFERS}

Analysis of the problem of innovative project management enables concluding that innovative management is quite promising if the strategy formulated by an enterprise depends on the life cycle of a product manufactured. Under conditions of severe price competitiveness, innovation management tends to focus on either reducing expenditures or increasing product quality through efficient control over technological innovations. The project scale conditions the group sizes in a project team, as more complicated innovations demand more complicated management structures.

Outstaffing in project management is efficient only in case of either low-qualified and service personnel or medium- and low-level managers. The problems of outstaffing application are associated with conditions, terms and the character of an agreement between an enterprise and a recruiter.

Under economic crisis conditions, it is advisable to apply anti-crisis projects accompanied by investigation of competitors' strategies.

\section{REFERENCES}

[1] M.A. Yokhna, and V.V. Stadnyk, "Innovative management". Kyiv: Akademvydav, 2006. [in Ukrainian].

[2] V.A. Rach, O.V. Rossoshanska, and O.M. Medvedeva, "Project management:practical aspects of implementing strategies of regional development”, Kyiv: K.I.S., 2010. [in Ukrainian].

[3] S. Rossol, “Outstaffing - is it profitable?”. [ebook]. - Available: http://www. businesscom.biz/outstaffing/about. [in Ukrainian].

[4] T.O. Skrypko, “Innovative management". Kyiv: Vyd-vo "Znannai”, 2011. [in Ukrainian].

[5] N.T. Tverezovska, and V.A. Kyshenko, "Project management: current state and prospects". [ebook]. Available: http://archive.nbuv.gov.ua/portal/soc_gum/VChdpu/ped/2012_100/Tv erez3.pdf.

[6] “Outstaffing”. [ebook]. Available: http://www.emergentpro.ru/servic es/additionalservices/outstuffing.html

[7] "Informational portal of innovation and business support". [Online]. Available: http://www.innovbusiness.ru.

[8] "Description of outsstaffing services". [Online]. Available: http://inform-profi.ru/sluga/pisanie/.

[9] S.M. Illiashenko, W. Strielkowski (eds.). "Innovative management: theoretical, methodical, and applied grounds", Prague: Prague Institute for Qualification Enhancement, 2018.

[10] K.O. Spiridonova, "Usage of outstaffing for increasing of efficiencz of Ukrainian companies", Eastern Europe: economics, business and 
governance, vol. 1, pp. 70-74, 2016. http://www.easterneuropeebm.in.ua/journal/1_2016/13.pdf 